\title{
Evidence for the involvement of peripheral $\beta$-adrenoceptors in delayed liquid gastric emptying induced by dipyrone, 4-aminoantipyrine, and antipyrine in rats
}

\author{
A.M. Vinagre ${ }^{2}$ and E.F. Collares ${ }^{1,2}$ \\ ${ }^{1}$ Departamento de Pediatria, Faculdade de Ciências Médicas, Universidade Estadual de Campinas, Campinas, SP, Brasil \\ ${ }^{2}$ Núcleo de Medicina e Cirurgia Experimental, Faculdade de Ciências Médicas, \\ Universidade Estadual de Campinas, Campinas, SP, Brasil
}

\begin{abstract}
Dipyrone (Dp), 4-aminoantipyrine (AA), and antipyrine (At) delay liquid gastric emptying (GE) in rats. We evaluated adrenergic participation in this phenomenon in a study in male Wistar rats $(250-300 \mathrm{~g})$ pretreated subcutaneously with guanethidine (GUA), $100 \mathrm{mg} \cdot \mathrm{kg}^{-1} \cdot$ day $^{-1}$, or vehicle $(\mathrm{V})$ for 2 days before experimental treatments. Other groups of animals were pretreated intravenously (iv) 15 min before treatment with $\mathrm{V}$, prazosin (PRA; $1 \mathrm{mg} / \mathrm{kg}$ ), yohimbine $(\mathrm{YOH} ; 3 \mathrm{mg} / \mathrm{kg})$, or propranolol (PRO; $4 \mathrm{mg} / \mathrm{kg}$ ), or with intracerebroventricular (icv) administration of $25 \mu \mathrm{g}$ PRO or $\mathrm{V}$. The groups were treated iv with saline or with $240 \mu \mathrm{mol} / \mathrm{kg} \mathrm{Dp}, \mathrm{AA}$, or At. GE was determined 10 min later by measuring the percentage of gastric retention (\%GR) of saline labeled with phenol red 10 min after gavage. \%GR (mean $\pm S E, n=8$ ) indicated that GUA abolished the effect of Dp (GUA vs $V=31.7 \pm 1.6$ vs $47.1 \pm 2.3 \%)$ and of At (33.2 \pm 2.3 vs $54.7 \pm 3.6 \%)$ on GE and significantly reduced the effect of $A A(48.1 \pm 3.2$ vs $67.2 \pm 3.1 \%$ ). PRA and $\mathrm{YOH}$ did not modify the effect of the drugs. $\% \mathrm{GR}$ (mean $\pm \mathrm{SE}, \mathrm{n}=8$ ) indicated that $i v$, but not $i c v$, PRO abolished the effect of Dp (PRO vs $\mathrm{V}=29.1 \pm 1.7$ vs $46.9 \pm 2.7 \%$ ) and At $(30.5 \pm 1.7$ vs $49 \pm 3.2 \%)$ and significantly reduced the effect of $\mathrm{AA}(48.4 \pm 2.6$ vs $59.5 \pm 3.1 \%)$. These data suggest activation of peripheral $\beta$-adrenoceptors in the delayed GE induced by phenylpyrazolone derivatives.
\end{abstract}

Key words: Gastric emptying; Dipyrone; 4-Aminoantipyrine; Antipyrine; Sympathetic nervous system; Adrenergic receptors

\section{Introduction}

The mechanisms involved in delayed gastric emptying (GE) of liquid in rats induced by the phenylprazolone derivatives dipyrone (Dp), 4-aminoantipyrine (AA), and antipyrine (At) are unknown, although there is evidence that 1) these drugs increase gastric compliance and 2) the vagus nerve, the central nervous system (CNS), and afferent capsaicin-sensitive pathways participate in the phenomenon (1-5).

The sympathetic nervous system (SNS), which has a limited effect on the gastrointestinal tract under physiological conditions, releases norepinephrine in postganglionic endings. Under certain conditions involving imbalanced homeostasis, acting as a defense mechanism, it interferes with the normal control of intestinal function, reducing motility and inhibiting secretion (6).

In the rat, the prevertebral sympathetic ganglia differ in organization from those of other species. The celiac ganglion and superior mesenteric ganglion project fibers toward the stomach, small intestine, and proximal colon. The stomach mostly receives fibers originating in the celiac ganglion (7).

Activation of the presynaptic $\alpha_{2}$-adrenoceptors located in the vagus nerve results in reduced acetylcholine release from cholinergic nerve endings. Activation of the $\alpha_{2 \mathrm{~B}}$-adrenoceptor subtype protects the gastric mucosa, and activation of the $\alpha_{2 A}$-adrenoceptor subtype may be responsible for the inhibition of GE in rats (8). On the other hand, $\beta_{1}$ - and $\beta_{2}$-adrenoceptors have been detected mainly in smooth muscle cells of the digestive tract of rats (9). An in vitro study revealed that, among the $\beta$-adrenergic subtypes, $\beta_{3}$-adrenoceptors are those that predominantly participate in the relaxation of the gastric fundus of rats induced by catecholamines (10).

Correspondence: E.F. Collares, Departamento de Pediatria, Faculdade de Ciências Médicas, UNICAMP, 13083-970 Campinas, SP, Brasil. E-mail: efcollares@hotmail.com 
Under certain experimental conditions involving delayed GE in rats, there is evidence that the condition can be partially or fully reversed by blockade of one of these adrenoceptors $(8,11-14)$. On this basis, considering that the SNS may interfere with the control of GE, it is reasonable to speculate about a possible SNS involvement in the phenomenon induced by phenylpyrazolone derivatives. In the present study, we evaluated adrenergic participation in the GE delay induced by Dp, AA, and At in rats by 1) acute adrenergic blockade induced by guanethidine and 2) adrenoceptor blockade by $\alpha$-adrenergic antagonists, and a nonselective $\beta$-adrenergic antagonist.

\section{Material and Methods}

The study was conducted on male Wistar rats weighing 250-300 g, and adapted to laboratory conditions for at least 2 weeks. The study was approved by the Ethics Committee for Animal Experimentation of Universidade Estadual de Campinas (UNICAMP; protocol No. 1372-1).

The animals were maintained in individual cages with free access to food until $24 \mathrm{~h}$ and water until $30 \mathrm{~min}$ before the evaluation of GE from 1:00 to $4: 00 \mathrm{pm}$. A similarly maintained group of animals was sedated with $75 \mathrm{mg} / \mathrm{kg}$ thiopental administered intraperitoneally (ip) 8 days before admission to the study and were implanted with a cannula in the right lateral ventricle, positioned as previously described (1).

Solutions of Dp, AA, At, guanethidine sulfate (GUA), prazosin (PRA), yohimbine (YOH), and propranolol (PRO), all from Sigma (USA), in sterile saline as the vehicle (V), were prepared at the time of use, and, when indicated,

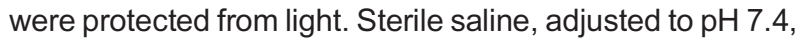
was used to prepare the GUA solution (15). The doses of each drug used were based on the literature and were tested in the laboratory in preliminary studies.

In the study of guanethidine-induced adrenergic blockade, the GUA group was pretreated with $100 \mathrm{mg} / \mathrm{kg}$ GUA administered subcutaneously $(s c)$ at $4: 00 \mathrm{pm}$ for 2 consecutive days, as indicated in the literature (15). Control animals ( $V$ group) received $1 \mathrm{~mL} / \mathrm{kg}$ saline vehicle by the same route.

In subsequent studies, a 15-min interval was allowed between pretreatment and treatment. Intravenous (iv) pretreatment with the $\alpha$-adrenergic antagonists was given to three groups as follows. The PRA group was pretreated with $1 \mathrm{mg} / \mathrm{kg}$ PRA (an $\alpha_{1}$ - and $\alpha_{2 B}$-adrenergic antagonist). The $\mathrm{YOH}$ group was pretreated with $3 \mathrm{mg} / \mathrm{kg} \mathrm{YOH}$ (a nonselective $\alpha_{2}$-adrenergic antagonist), and a control group was pretreated with $1 \mathrm{~mL} / \mathrm{kg}$ saline ( $\mathrm{V}$ group). The $\mathrm{PRA}$ and $\mathrm{YOH}$ doses used were those recommended in the literature (11), which correspond approximately to 8 and 1.5 times higher values, respectively, than those employed iv in a study of the effect of $\alpha$-adrenergic agonists on gastric motility in rats (16).
The animals pretreated with the nonselective $\beta$-adrenergic antagonist propranolol (PRO group) were pretreated iv with $4 \mathrm{mg} / \mathrm{kg}$ of the drug, a dose determined in a preliminary study from our laboratory, and the control group was pretreated with $1 \mathrm{~mL} / \mathrm{kg}$ saline vehicle ( $\mathrm{V}$ group).

For intracerebroventricular (icv) pretreatment with propranolol, $25 \mu \mathrm{g} /$ animal (PRO group) or $10 \mu \mathrm{L}$ saline ( $V$ group) was used. The technique used and the volume administered were established in previous studies from our laboratory $(1,3,4)$, and the dose of propranolol was determined in a preliminary study that showed that higher doses result per se in a discrete and progressive delay of GE that might compromise the study.

As done in previous studies (1-5), all groups were treated iv with $240 \mu \mathrm{mol} / \mathrm{kg} \mathrm{Dp}, \mathrm{AA}$, or At or with $1 \mathrm{~mL} / \mathrm{kg}$ sterile saline solution (S) vehicle control, and GE was determined 10 min after treatment.

GE was assessed indirectly in awake animals by determining the percentage of gastric retention (\%GR) of a saline test meal labeled with $60 \mu \mathrm{g} / \mathrm{mL}$ phenol red $10 \mathrm{~min}$ after administration by gavage in a volume of $2 \mathrm{~mL} / 100 \mathrm{~g}$ rat weight according to a technique standardized in our laboratory (17), with some modifications (5).

In the animals implanted with a cannula in the lateral ventricle, the location of the cannula was determined by icv injection of $10 \mu \mathrm{L} 1 \%$ Evans blue solution at the end of the GE study. After the rats in this group were killed, their brains were removed and fixed in $10 \%$ formalin. Coronal sections were obtained and icv injection was confirmed by detection of the dye in the IV ventricle, as done in previous studies (1-4).

Data were analyzed statistically by ANOVA and pair comparisons were performed using the Tukey test, with the level of significance set at $\alpha=0.05$ for both tests.

\section{Results}

Figure 1 illustrates the results of $s c$ pretreatment with GUA (\%GR, mean \pm SE, $n=8)$, which did not modify GE in the animals treated with vehicle $(29.5 \pm 1.3 \%)$ compared to their controls $(24.9 \pm 1.8 \%)$. On the other hand, pretreatment with GUA abolished the effect of Dp $(31.7 \pm 1.6 \%)$ and At $(33.2 \pm 2.3 \%)$ compared with the controls pretreated with vehicle $(47.1 \pm 2.3$ and $54.7 \pm 3.6 \%$, respectively) and significantly reduced the effect of AA $(48.1 \pm 3.2 \%)$ compared with controls $(67.3 \pm 3.1 \%)$.

The results of \%GR (Table 1) for rats pretreated iv with $\mathrm{PRA}$ or $\mathrm{YOH}$ and treated with $\mathrm{Dp}, \mathrm{AA}$, or At did not differ significantly from those of rats pretreated with vehicle and treated with the same drugs. The animals pretreated with $\mathrm{PRA}$ or $\mathrm{YOH}$ and treated with saline did not differ significantly from those pretreated with $\mathrm{V}$ and then treated with $\mathrm{S}$.

Figure 2 illustrates the results of iv pretreatment with $\mathrm{PRO}$. The $\% \mathrm{GR}$ values (mean $\pm \mathrm{SE}, \mathrm{n}=8$ ) showed that this pretreatment did not modify $G E$ in animals 


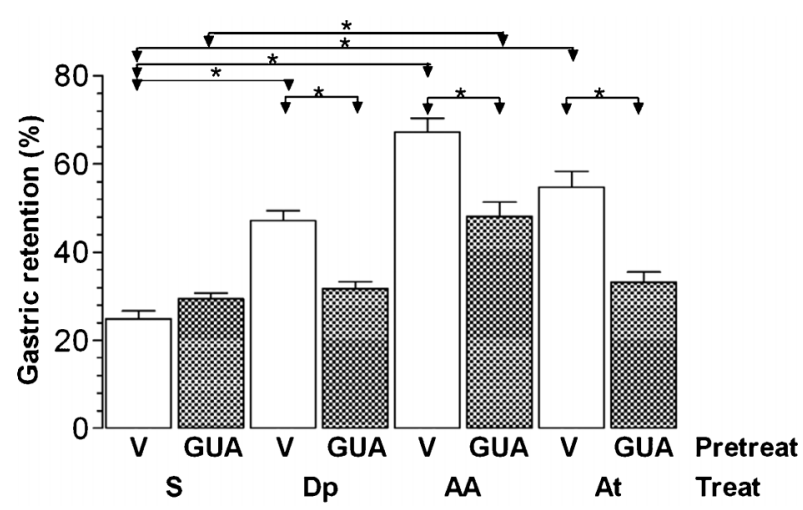

Figure 1. Gastric retention (\%) of a saline test meal 10 min after administration to rats by gavage. The animals were pretreated (Pretreat) $s c$ with saline as a vehicle $(V)$ or with guanethidine sulfate (GUA, $100 \mathrm{mg} \cdot \mathrm{kg}^{-1} \cdot \mathrm{day}^{-1}$ ) for 2 days before the iv treatments (Treat) with saline (S) or $240 \mu \mathrm{mol} / \mathrm{kg}$ dipyrone (Dp), 4-aminoantipyrine (AA) or antipyrine (At). The test meal was administered 10 min after the treatment. Data are reported as means \pm SE for 8 animals per group. ${ }^{*} \mathrm{P}<0.05$ (Tukey test).

subsequently treated iv with $\mathrm{S}(24.6 \pm 1.2 \%)$ compared with their controls $(25.5 \pm 1.6 \%)$. In contrast PRO pretreatment abolished the effects of Dp $(29.1 \pm 1.7 \%)$ and At $(30.5 \pm 1.7 \%)$ compared with their controls pretreated with $\mathrm{V}(46.9 \pm 2.7$ and $49 \pm 3.2 \%$, respectively), and significantly reduced the effect of $\mathrm{AA}(48.4 \pm 2.6 \%)$ compared with controls $(59.5 \pm 3.1 \%)$.

The mean \pm SE \%GR in rats $(n=8)$ pretreated with $25 \mu \mathrm{g} /$ animal PRO icv and then treated iv with Dp $(53.2 \pm 2.8 \%), \mathrm{AA}(54.2 \pm 3.9 \%)$, or At $(44.4 \pm 2.5 \%) \mathrm{did}$ not differ significantly from that observed in rats pretreated icv with vehicle $(10 \mu \mathrm{L} /$ animal) and treated with the same drugs $(50.1 \pm 2.0,58.2 \pm 2.8$, and $44.9 \pm 3.4 \%$, respectively). The \%GR in animals pretreated with PRO and treated with $S(31.2 \pm 2.1 \%)$ did not differ from that in animals pretreated with $\mathrm{V}$ and treated with $\mathrm{S}(25.3 \pm 1.4 \%)$.

\section{Discussion}

Treatment with guanethidine sulfate for a few days blocks the release of norepinephrine from peripheral

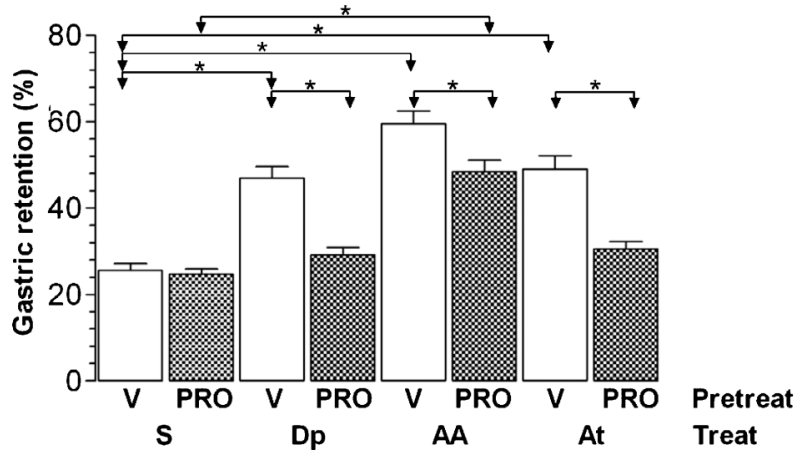

Figure 2. Gastric retention (\%) of a saline test meal $10 \mathrm{~min}$ after administration to rats by gavage. The animals were pretreated (Pretreat) iv with saline as a vehicle (V) or with $4 \mathrm{mg} / \mathrm{kg}$ propranolol (PRO), $15 \mathrm{~min}$ before the iv treatments (Treat) with saline (S) or $240 \mu \mathrm{mol} / \mathrm{kg}$ dipyrone (Dp), 4-aminoantipyrine (AA) or antipyrine (At). The test meal was administered $10 \mathrm{~min}$ after the treatment. Data are reported as means \pm SE for 8 animals per group. ${ }^{*} \mathrm{P}<0.05$ (Tukey test).

sympathetic nerves in adult rats (15). In the present study, sc pretreatment with this drug $(100 \mathrm{mg} / \mathrm{kg})$ for 2 days (15) abolished the delayed GE of a liquid meal induced by dipyrone and antipyrine and significantly reduced, but did not abolish, the effect of 4-aminoantipyrine (Figure 1), suggesting the involvement of the SNS in this phenomenon.

Pretreatment with prazosin, an $\alpha_{1}$ - and $\alpha_{2 \mathrm{~B}}$-adrenergic antagonist, or yohimbine, a nonselective $\alpha_{2}$-adrenergic antagonist $(8,16)$, did not interfere with the effect of the three phenylpyrazolone derivatives on GE (Table 1), indicating that the participation of these receptors in the delay is unlikely.

Similar to the results obtained with guanethidine, pretreatment with propranolol, a classical nonselective $\beta$-adrenergic antagonist (18), abolished the effect of dipyrone and antipyrine on GE and significantly reduced, but did not abolish, the effect of 4-aminoantipyrine (Figure 2 ), indicating that the peripheral adrenergic receptors involved may be $\beta$-adrenergic.

However, considering that propranolol is highly lipophilic and rapidly crosses the blood-brain barrier (19), the results may also be due, at least in part, to its action on

Table 1. Fractional gastric retention (\%GR) of a liquid meal (saline) $10 \mathrm{~min}$ after administration to rats by gavage.

\begin{tabular}{lcccr}
\hline Pretreatment (iv) & \multicolumn{3}{c}{ Treatment (iv) } \\
\cline { 2 - 5 } & S & Dp & AA & At \\
\hline V & $28.4 \pm 1.1$ & $51.0 \pm 2.2^{\mathrm{a}}$ & $62.5 \pm 3.1^{\mathrm{a}}$ & $49.7 \pm 3.4^{\mathrm{a}}$ \\
PRA & $21.9 \pm 1.0$ & $49.0 \pm 3.8^{\mathrm{b}}$ & $64.1 \pm 2.8^{\mathrm{b}}$ & $50.0 \pm 5.1^{\mathrm{b}}$ \\
YOH & $34.6 \pm 1.3$ & $49.6 \pm 3.6^{\mathrm{c}}$ & $52.1 \pm 4.6^{\mathrm{c}}$ & $51.2 \pm 3.8^{\mathrm{c}}$ \\
\hline
\end{tabular}

Data are reported as mean \pm SE \%GR for 8 rats. The animals were pretreated with saline as a vehicle (V), $1 \mathrm{mg} / \mathrm{kg}$ prazosin (PRA) or 3 $\mathrm{mg} / \mathrm{kg}$ yohimbine $(\mathrm{YOH})$ and treated with saline (S), $240 \mu \mathrm{mol} / \mathrm{kg}$ dipyrone (Dp), $240 \mu \mathrm{mol} / \mathrm{kg}$ 4-aminoantipyrine (AA) or $240 \mu \mathrm{mol} / \mathrm{kg}$ antipyrine (At). $\mathrm{P}<0.05 \mathrm{vs}^{\mathrm{a}} \mathrm{V}+\mathrm{S},{ }^{\mathrm{b}} \mathrm{PRA}+\mathrm{S}$, and ${ }^{\mathrm{C}} \mathrm{YOH}+\mathrm{S}$, respectively (Tukey test). 
the CNS. In rats, $\beta_{1}$ - and $\beta_{2}$-adrenoceptors have been identified in various regions of the CNS (20). However, since icv administration of the nonselective $\beta$-antagonist did not modify the effect of the three study drugs, this hypothesis is unlikely. On the other hand, this observation supports the possibility of participation of peripheral $\beta$ adrenoceptors in this phenomenon.

On the basis of the experimental conditions of the present study, it is clear that the adrenergic blockade induced by guanethidine and propranolol did not abolish the effect of 4-aminoantipyrine. Thus, it is possible that another mechanism in addition to the activation of $\beta$-adrenergic receptors may participate in the effect of this drug on GE.

Previous reports have shown the involvement of $\beta$-adrenoceptors in other situations where GE has been altered experimentally. In rat models of motion sickness (12)

\section{References}

1. Collares EF, Vinagre AM. Evidence of the effect of dipyrone on the central nervous system as a determinant of delayed gastric emptying observed in rats after its administration. Braz J Med Biol Res 2003; 36: 1375-1382, doi: 10.1590/ S0100-879X2003001000014.

2. Collares EF, Vinagre AM. Effect of the GABAB agonist baclofen on dipyrone-induced delayed gastric emptying in rats. Braz J Med Biol Res 2005; 38: 99-104, doi: 10.1590/ S0100-879X2005000100015.

3. Soares AC, Vinagre AM, Collares EF. Effect of antipyrine on the gastric emptying of liquid in rats. Braz J Med Biol Res 2006; 39: 1507-1512, doi: 10.1590/S0100-879X2006001100015.

4. Vinagre AM, Collares EF. Effect of 4-aminoantipyrine on gastric compliance and liquid emptying in rats. Braz $J$ Med Biol Res 2007; 40: 903-909, doi: 10.1590/S0100-879X2006005000119.

5. Vinagre AM, Collares EF. Phenylpyrazolone derivatives inhibit gastric emptying in rats by a capsaicin-sensitive afferent pathway. Braz J Med Biol Res 2009; 42: 10861089, doi: 10.1590/S0100-879X2009001100014.

6. Barrett KE. Neurohumoral regulation of gastrointestinal function. In: Barrett KE (Editor), Gastrointestinal physiology. New York: Lange Medical Books/McGraw-Hill; 2006. p 18-36.

7. Szurszewski JH, Linden DR. Physiology of prevertebral sympathetic ganglia. In: Johnson LR (Editor), Physiology of the gastrointestinal tract. 5th edn. Oxford: Elsevier Inc.; 2012. p 583-627.

8. Fulop K, Zadori Z, Ronai AZ, Gyires K. Characterisation of alpha2-adrenoceptor subtypes involved in gastric emptying, gastric motility and gastric mucosal defence. Eur J Pharmacol 2005; 528: 150-157, doi: 10.1016/j.ejphar.2005.10.025.

9. Yu O, Ouyang A. Distribution of beta-adrenoceptor subtypes in gastrointestinal tract of nondiabetic and diabetic BB rats. A longitudinal study. Dig Dis Sci 1997; 42: 1146-1153, doi: 10.1023/A:1018877318101.

10. Ozakca I, Arioglu E, Guner S, Altan VM, Ozcelikay AT. Role of beta-3-adrenoceptor in catecholamine-induced relaxations in gastric fundus from control and diabetic rats. Pharmacology 2007; 80: 227-238, doi: 10.1159/000104876.

11. Gondim FA, Rodrigues CL, da Graca JR, Camurca FD, de and restraint stress (13) in which GE is reduced, propranolol blocked the effect of the procedure. Another observation demonstrated that $\beta_{3}$-adrenceptors play an important role in the inhibition of GE caused by restraint stress in rats, whereas nonspecific adrenoceptors are involved in the GE inhibition induced by treatment with norepinephrine (14). Since propranolol has high affinity for the $\beta_{1}$ - and $\beta_{2^{-}}$ adrenoceptor subtypes and low affinity for the $\beta_{3}$-adrenergic subtype (18), at this stage of our study we cannot yet conclude which subtype or subtypes are involved.

\section{Acknowledgments}

Research supported by Fundo de Apoio ao Ensino, à Pesquisa e Extensão (FAEPEX), Universidade Estadual de Campinas, Campinas, SP, Brasil.
Alencar HM, dos Santos AA, et al. Neural mechanisms involved in the delay of gastric emptying and gastrointestinal transit of liquid after thoracic spinal cord transection in awake rats. Auton Neurosci 2001; 87: 52-58, doi: 10.1016/ S1566-0702(00)00261-7.

12. Gupta YK, Chaudhary G. Effect of antiemetic drugs on decrease in gastric emptying in experimental model of motion sickness in rats. Acta Pharmacol Sin 2003; 24: 296-300.

13. Nakade $Y$, Tsuchida D, Fukuda H, Iwa M, Pappas TN, Takahashi T. Restraint stress delays solid gastric emptying via a central CRF and peripheral sympathetic neuron in rats. Am J Physiol Regul Integr Comp Physiol 2005; 288: R427R432, doi: 10.1152/ajpregu.00499.2004.

14. Tsukada F, Nagura Y, Abe S, Sato N, Ohkubo Y. Effect of restraint and footshock stress and norepinephrine treatment on gastric emptying in rats. Biol Pharm Bull 2003; 26: 368370, doi: 10.1248/bpb.26.368.

15. Navegantes LC, Resano NM, Migliorini RH, Kettelhut IC. Effect of guanethidine-induced adrenergic blockade on the different proteolytic systems in rat skeletal muscle. Am J Physiol 1999; 277: E883-E889.

16. Zadori ZS, Shujaa N, Fulop K, Dunkel P, Gyires K. Pre- and postsynaptic mechanisms in the clonidine- and oxymetazolineinduced inhibition of gastric motility in the rat. Neurochem Int 2007; 51: 297-305, doi: 10.1016/j.neuint.2007.06.027.

17. Bucaretchi F, Collares EF. Effect of Phoneutria nigriventer spider venom on gastric emptying in rats. Braz $J$ Med Biol Res 1996; 29: 205-211.

18. Ursino MG, Vasina V, Raschi E, Crema F, De Ponti F. The $\beta_{3}$-adrenoceptor as a therapeutic target: Current perspectives. Pharmacol Res 2009; 59: 221-234, doi: 10.1016/ j.phrs.2009.01.002

19. McAinsh J, Cruickshank JM. Beta-blockers and central nervous system side effects. Pharmacol Ther 1990; 46: 163-197, doi: 10.1016/0163-7258(90)90092-G.

20. Nicholas AP, Hokfelt T, Pieribone VA. The distribution and significance of CNS adrenoceptors examined with in situ hybridization. Trends Pharmacol Sci 1996; 17: 245-255, doi: 10.1016/0165-6147(96)10022-5. 